\title{
Electrocardiographic and Echocardiographic Changes in Cameroonian Hypertensive Patients
}

\author{
Olivier Pancha Mbouemboue ${ }^{1,2, ~ *, ~ H e r m a n ~ C a b r e l ~ N g a n g a o ', ~ W a v o u l a n s a ~ Z o u r m b a ~}{ }^{1}$, \\ Ahmadou Hayatou ${ }^{1,2}$ \\ ${ }^{1}$ Department of Biomedical Sciences, Faculty of Science, University of Ngaoundere, Ngaoundere, Cameroon \\ ${ }^{2}$ Ngaoundere Regional Hospital, Ngaoundere, Cameroon

\section{Email address:} \\ olivier_pancha@yahoo.fr (O. P. Mbouemboue),ngangaocabrel@gmail.com (H. C. Ngangao), wavoulansa@gmail.com (W.Zourmba), \\ ahmadouhayat@gmail.com (A. Hayatou) \\ ${ }^{*}$ Corresponding author
}

\section{To cite this article:}

Olivier Pancha Mbouemboue, Herman Cabrel Ngangao, Wavoulansa Zourmba, Ahmadou Hayatou. Electrocardiographic and Echocardiographic Changes in Cameroonian Hypertensive Patients. Cardiology and Cardiovascular Research. Vol. 5, No. 2, 2023, pp. 57-60. doi: 10.11648/j.ccr.20210502.11

Received: April 6, 2021; Accepted: April 22, 2021; Published: May 8, 2021

\begin{abstract}
High blood pressure is a major cardiovascular risk factor. It has repercussions on the heart, which can be easily assessed by non-invasive examinations. The objective of this study was to describe electrocardiographic and echocardiographic abnormalities in hypertensive patients under follow up at the Ngaoundere Regional Hospital, (Cameroon). The study was analytical and cross-sectional in nature. It was carried out at the Ngaoundere Regional Hospital (Cameroon). All known adult hypertensive patients who had a resting electrocardiogram (ECG) and echocardiography done during their follow up were included in the study. The study population consisted of 200 hypertensive patients. The mean age of the patients was $59 \pm 1.6$ years with extremes of 25 and 85 years. Of all the ECGs performed, a total of $94 \%$ had abnormal findings. The most frequent electrocardiographic abnormalities were cardiac arrhythmias (53.5\%), and left ventricular hypertrophy (LVH) (22\%). Overall, $91 \%$ of the cardiac echography performed had abnormal findings most of which were ventricular hypertrophy, diastolic dysfunction and left atrial enlargement. In conclusion: a wide variety of electrocardiographic and echocardiographic abnormalities are diagnosed in the hypertensive patient in our environnement. None of them should be neglected. They all present, although to varying degrees, an interest in the orientation and organization of the therapeutic strategy of patients with hypertension. The use of ECG and echocardiography for this purpose should be encouraged in resource-limited areas.
\end{abstract}

Keywords: ECG Abnormalities, Echocardiographic Abnormalities, Hypertension, Cameroon

\section{Introduction}

High blood pressure is a major cardiovascular risk factor [1-3]. It is responsible for approximately $13.5 \%$ of global mortality and is the fourth leading cause of premature death in developing countries $[4,5]$. It has repercussions on the heart, the assessment of which makes it possible to evaluate the cardiovascular risk profile in hypertensive patients. Whether cardiac arrhythmias or structural abnormalities of the left ventricle, several studies have shown that they can be responsible for major cardiovascular events $[6,7]$.

This study aimed at assessing electrocardiographic and echocardiographic data of hypertensive patients under follow-up at the Regional Hospital of Ngaoundere in Cameroon.

\section{Material and Methods}

\subsection{Study Design and Data Collection}

This was a cross-sectional, analytical study carried out at the Ngaoundere Regional Hospital from January to August 2019; known adult hypertensive patients, under followed up at the Ngaoundere Regional Hospital for at least three months, who had an ECG and a cardiac ultrasound done were 
included in the study. The basic clinical characteristics of the patients were obtained using the participants' medical records. The clinical data obtained were analyzed for age, gender, clinical signs of hypertension, cardiovascular complications (renal failure, heart failure, and stroke), comorbidities, ECG and echocardiographic data.

The resting ECG was performed using a Cardimax FX 1111 machine (Fukuda Denshi Co. Ltd., Japan). Echocardiography was performed using standard transthoracic view with a Sonoscape 9 machine, (Sonoscape Medical Corporation, Shensen China). The measurements were performed according to the recommendations of the American Society of Echocardiography [8,9]. The image quality criteria used were those for the CARDIA Study [10]. All images were of good quality thereby facilitating their interpretation. The criteria for left ventricular hypertrophy were those described by Hammond IW et al. [11]. For the evaluation of the left ventricular diastolic function, the pulsed Doppler flow was measured in the apical four chamber view, with the cursor placed near the mitral and the aortic flow. The heights of the E and A waves were calculated. Valvular regurgitation was evaluated with color Doppler imaging; stenosis and valve insufficiency were the only valvular abnormalities considered.

Left ventricular ejection fraction greater than $55 \%$ was considered normal. Pulmonary hypertension was defined as a pulmonary pressure above $18 \mathrm{mmHg}$ [12]. ECG and Echocardiography was performed and interpreted under the supervision of a cardiologist coauthor.

\subsection{Statistical Analysis}

The data were analyzed using SPSS $20.0 ®$ software. The statistical methods used were the calculation of proportions for qualitative variables and the calculation of mean and standard deviations for quantitative variables.

\subsection{Ethical Consideration}

Before their enrollment, a written consent was obtained from all participants after being adequately informed about the study goal. The study was approved by the ethical committee of the Ngaoundere Regional Hospital (Ref. 2152/L/RC/RA/DSP/HR/NGD/CLE) and the Ngaoundere Urban Health District (Ref. 674/AS/RA/DV/NGDU).

\section{Results}

A total of 200 patients were included in the study. The mean age of the patients was $59 \pm 1.6$ years with extremes of 25 and 85 years. The most represented age group was the 5060 year olds. The sex-ratio was 1.5 in favor of women. Hypertension was associated with diabetes in $14.5 \%$ of patients $(n=29)$, heart failure in $5.5 \%$ of patients $(n=11)$ and kidney failure in $1.5 \%$ of patients $(n=3)$. Of the patients included in the study, $17 \%(n=34)$ had a history of stroke. The most common clinical signs of high blood pressure were occipital headache, dizziness and dyspnea.
Out of the overall 200 ECGs performed, 94\% had abnormal results. The most common abnormalities were heart rhythm disorders $(53.5 \%)$, and left ventricular hypertrophy $(22 \%)$. In total, $91 \%$ of the cardiac echography performed had an abnormality. The most prevalent echocardiographic abnormalities were left ventricular diastolic dysfunction (67.5\%), LVH (55.5\%) and left atrial enlargement (12\%). The main electrocardiographic and echocardiographic abnormalities observed in this study are presented in Tables 1 and 2.

Table 1. Main Electrocardiographic abnormalities in study patients.

\begin{tabular}{lll}
\hline ECG abnormalities & $\mathbf{N = 2 0 0}$ & $\mathbf{\%}$ \\
\hline Arrhytmias (ALL) & 107 & 53.5 \\
Sinus tachycardia & 17 & 8.5 \\
SPB* & 2 & 1 \\
Sinus node dysfonction & 1 & 0.5 \\
Atrial fibrillation & 5 & 2.5 \\
Sinus arrhythmia & 12 & 6 \\
VPB** & 16 & 8 \\
Sinus bradycardia & 19 & 9.5 \\
Atrioventricular block & 3 & 1.5 \\
Right bundle branch block & 12 & 6 \\
Left bundle branch block & 9 & 4.5 \\
Left anterior hemiblock & 7 & 3.5 \\
Intraventricular conduction delay & 3 & 1.5 \\
Left ventricular hypertrophy & 44 & 22 \\
ST depression & 15 & 7.5 \\
\hline
\end{tabular}

*supraventricular premature beat, **ventricular premature beat

Table 2. Main echocardiographic abnormalities in study patients.

\begin{tabular}{lll}
\hline Echocardiographic abnormalities & $\mathbf{N = 2 0 0}$ & $\mathbf{\%}$ \\
\hline Dilatation of the left ventricle & 24 & 12 \\
Dilatation of the right ventricle & 6 & 3 \\
Diastolic dysfunction & 135 & 67.5 \\
Left ventricular hypertrophy & 111 & 55.5 \\
Mitral regurgitation & 50 & 26 \\
Aortic regurgitation & 16 & 8 \\
Pulmonary hypertension & 4 & 2 \\
Tricuspide regurgitation & 7 & 3.5 \\
Impaired left ventricular dysfunction & 8 & 4 \\
\hline
\end{tabular}

\section{Discussion}

This study aimed at describing ECG and echocardiographic abnormalities in hypertensive patients under follow up in a resource limited area in Sub-Saharan African setting.

ECG provides numerous information on the heart in hypertensive patients, and has good specificity in the detection of LVH, whose early diagnosis is necessary to establish the risk profile of the hypertensive patient. In this study, left ventricular hypertrophy accounted for $26 \%$ of the electrocardiographic abnormalities observed. This result is higher than the one reported by Cuspidi et al., (24\%) [13] but lower than that found in the study by Agomuoh and Odia (37.1\%) [14]. This can be explained by differences in the clinical profile of patients.

LVH was not by far the only electrocardiographic abnormality observed. We observed in this study various 
forms of cardiac arrhythmias: extrasystoles, bradycardia, sinus tachycardia, supraventricular arrhythmias in particular. According to the literature review, these complications are frequent in hypertensive patients [15]. They have an impact on the patient's quality of life and can require adaptation of the patient's management [16]. In total, arrhythmias were recorded in $53.5 \%$ of patients in our study; this result is in line with the one of Ejim et al. who reported significant proportion of rhythm disturbances in hypertensive subjects in a study in Nigeria [17].

Cardiac ultrasound was used for the evaluation of the left ventricle structure and function in the study population. LVH is one of the abnormalities frequently found during echocardiographic examination of the hypertensive patient. However, its prevalence varies depending on authors. In the study by Tovillas Moran et al [18] the prevalence rate of LVH was $63.8 \%$, while in the study by Wang S-X et al [19] it was $42.7 \%$. In our study, it was observed in $55.5 \%$ of participants.

Dilatation of the left atrium and diastolic dysfunction of the left ventricle were the other main two echocardiographic abnormalities found in the study population. The left atrium is the cardiac cavity most prone to remodeling in hypertensive patients [20]. Its size is correlated with cardiovascular complications, and strongly associated with left ventricular hypertrophy and diastolic dysfunction [21]. Dilatation of the left atrium was observed in $12 \%$ of participants in this work.

Diastolic dysfunction is a common situation in hypertensive patients. It is an early cardiac manifestation that precedes the detection of left ventricular hypertrophy on the ECG [22] in hypertensive patients; far from being a benign manifestation, it can be associated with serious cardiovascular complications. According to literature review the mortality rate related to left ventricular diastolic dysfunction varies from $5 \%$ to $26 \%$ depending on the degree of diastolic dysfunction [23]. In our study, the prevalence rate of diastolic dysfunction was $67.5 \%$. This is higher than the $45.6 \%$ reported in a study by Zanchetti et al. in a study in elderly hypertensive patients [24]. The divergence of our data and those from this study may be explained by the difference of diastolic dysfunction criteria used in both studies.

In a study in elderly hypertensive patients, its prevalence was estimated at $25.8 \%$ and $45.6 \%$ depending on the diagnostic criterion used [24]. It was $67.5 \%$ in the present study.

\section{Conclusion}

Electrocardiographic and echocardiographic abnormalities are numerous and varied in the hypertensive patient in our environment. The high prevalence of left ventricular hypertrophy, diastolic dysfunction and atrial dilatation found in this work should not lead to neglecting the heart rhythm disorders observed. They are just as important for orienting and organizing the therapeutic strategy of the hypertensive patient.

\section{Conflict of Interest}

The authors declare that they have no competing interests.

\section{Acknowledgements}

Authors thank all medical personnel who make this study possible.

\section{References}

[1] Abu-Saad, Chetrit A, Eilat- Adar S, Alpert G, Atama A, Gilon-Keren $\mathrm{M}$ et al. Blood Pressure Level and Hypertension Awareness and Control Differ by Marital Status, Sex, and Ethnicity: A Population-Based Study. Am J Hypertens. 2014; 27 (12), 1511-20

[2] Katte J-C, Dzudie A, Sobgnwi E, Mbong EN, Festse GT, Kouam Koouam C, Kengne AP Coincidence of diabetes mellitus and hypertension in a semi-urban Cameroonian population: a cross sectional study. BMC Public Health 14; (2014), 696.

[3] Wang J, Zhang L, Wang F, Liu L, Wang H. Prevalence, awareness, treatment, and control of hypertension in China: results from a national survey. Am J Hypertens. 2014; 27 (11), 1355-61.

[4] Arabzadeh S, Sadeghi M, Rabiei K, Sarrafzadegan N, Taheri L, Golshani J. Determinants of uncontrolled hypertension in Iranian population. ARYA Atheroscler. 2014; 10 (1), 25-31.

[5] Global Atlas on the Prevention and Control of Cardiovascular Disease. Mendis S, Pushka P, Norrving B Editors. World Health Organization, Geneva, 2011.

[6] Chatterjee S, Bavishi C, Sardar P, Agarwal V, Krishnamoorthy P, Grodzicki T, et al. Meta-analysis of left ventricular hypertrophy and sustained arrhythmias. Am J Cardiol 2014; 1,114: 1049-52.

[7] Haider AW, Larson MG, Benjamin EJ, Levy D. Increased left ventricular mass and hypertrophy are associated with increased risk for sudden death. J Am Coll Cardiol 1998; 32: 1454-9.

[8] Marwick TH, Gillebert TC, Aurigemma G, Chirinos J, Derumeaux G, Galderisi $M$ et al. Recommandations on the Use of Echocardiograhy in Adult Hypertension: A Report from the European Association of Cardiovascular Imaging (EACVI) and the American Society of Echocardiography. J Am Soc Echocardiogr 2015; 28: 727-54.

[9] Mitchell C, Rahko PS, Blauwet LA, Canaday B, Finstuen JA, Forster MC, Horton K, Ogunyankin KO, Palma RA, Velazquez EJ. Guidelines for Performing o Comprehensive Transthoracic Echocardiographic Examination in Adults. J Am Soc Echocardiogr. 2019; Jan; 32 (1): 1-64.

[10] Gardin JM, Wagenknect LE, Culver HA, Flack J, Gidding S, Kurosaki T, et al. Relationship of cardiovascular risk factors to echocardiographic left ventricular mass in healthy young black and white adult men and women. The CARDIA study. Coronary Artery Risk Development in Young Adults. Circulation 1995; 92: 380-387. 
[11] Hammond IW, Deverereux RB, Alderman MH, Lutas EM, Spitzer MC, Crowley JS et al. The prevalence and correlates of echocardiographic left ventricular hypertrophy among employed patients with uncomplicated hypertension. J Am Coll Cardiol 1986; 7: 639-650.

[12] Badesch DB, Champion HC, Gomez Sanchez MA, Hoepper MM, Loyd JE, Manes A et al. Diagnosis and assessment of pulmonary arterial hypertension J Am Coll Cardiol. 2009; 54 (1 Suppl): S55-S66.

[13] Cuspidi C, Rescaldini M, Sala C, Negri F, Grassi G, Mancia G. Prevalence of electrocardiographic left ventricular hypertrophy in human hypertension: an update review. J Hypertension 2012. 30 (11): 2066-73.

[14] Agomuoh DI and Odia OJ. Pattern of ECG abnormalities in Nigerian hypertensive patients seen in University of Port Harcourt Teaching hospital. Port Harcourt Medical Journal 2007; 2 (1) 22-26.

[15] Afzal MR, Savona S, Mohamed O, Mohamed-Osman A, Kalbefleisch SJ. Hypertension and arrhythmias. Heart Fail Clin 2019; 15 (4): 543-550.

[16] Le HeuzeyJY, Guize L. Cardiac prognosis in hypertensive patients. Am J Med 1988; 84: 65-8.

[17] Ejim EC, Ike SO, Anisiuba BC, Essien IO, Onwubere BJ, Ike VO. Cardiac arrhythmias in recently diagnosed hypertensive patients at first presentation: an electrocardiographic- based study. Niger J Med. Jan-Mar; 2012, 21 (1): 6-10.

[18] Tovillas-Morán FJ, Zabaleta-del-Olmo E, Dalfó-Baqué A.
Cardiovascular morbidity and mortality and left ventricular geometric patterns in hypertensive patients treated in primary care. Rev EspCardiol. 2009; 62 (3): 246-254.

[19] Wang S-X, Xue H, Zou YB, Sun K, Fu CY, Wang H et al Prevalence and risk factors for left ventricular hypertrophy and left ventricular geometric abnormality in the patients with hypertension among Han Chinese. Chin Med J 2012; 125 (1): 21-26.

[20] Kirchhof P, Benussi S, Kochecha D, Ahlsson A, Atar D, Casadei B. et al. 2016 ESC Guidelines for the management of atrial fibrillation developed in collaboration with EACTS. EurHeart J 2016; 37: 2893-962.

[21] Cuspidi C, Negri F, Sala C, Valerio C Mancia G. Association of left atrial enlargement with left ventricular hypertrophy and diastolic dysfunction: a tissue Doppler study in echocardiographic practice. Blood Press. 2012; 21: 24-30.

[22] Smith VE, Schulman P, Karimeddini MK, White WB, Meeran MK, Katz AM. Rapid ventricular filling in left ventricular hypertrophy: II. Pathologic hypertrophy. J Am Coll Cardiol. 1985; 5 (4): 869-874.

[23] Redfield MM, Jaconsen SJ, Burnett JC Jr, Mahoney DW, Bailey KR, Rodeheffer RJ. Burden of sytolic and diastolic dysfunction in the community: appreciating the scope of the heart failure epidemic. JAMA. 2003; 289 (2): 194-202.

[24] Zanchetti A, Cuspidi C, Comarella L, Rosei EA, Ambrosini, $\mathrm{E}$, Chiariello $\mathrm{M}$ et al. Left ventricular diastolic dysfunction in elderly hypertensives: results of the APROS diadys-study Journal of Hypertension 2007, 25 (10) 2158-2167. 